\title{
Lucha por la preservación de la riqueza identitaria, natural, arqueológica y arquitectónica de los pueblos
}

Fight for the preservation of the identity, natural, archaeological and architectural wealth of towns

\author{
Aleyda Rosa Reina Reyes Ortega \\ reynareyes266@hotmail.com \\ Código ORCID: 0000-0001-5864-9759 \\ Universidad San Francisco Xavier de Chuquisaca \\ Sucre - Bolivia
}

Los museos y el turismo comunitario se convierten en una estrategia para preservar, rescatar y revalorizar el patrimonio turístico cultural. El objetivo de la investigación fue analizar la importancia de los museos comunitarios en Potosí - Bolivia, para la preservación de la riqueza de los pueblos y el fortalecimiento del turismo. Responde a un estudio de tipo cualitativo, de corte transversal y alcance descriptivo que aplicó la metodología etnográfica en tres distritos rurales del municipio de Potosí: Huari Huari, Paranturi y Manquiri.

Los resultados evidencian: riqueza patrimonial que data de la época de la colonia; esfuerzos públicos insuficientes destinados a la preservación del patrimonio histórico; conocimiento, preocupación e interés al respecto por parte de los comunarios. Se concluye que hay necesidad de fortalecer el turismo comunitario y contar con estrategias políticas que preserven y resguarden el patrimonio presente en la riqueza identitaria, natural, arqueológica y arquitectónica de los pueblos.

Palabras clave: Museo comunitario; Turismo; Preservación; Patrimonio; Cultural

\begin{abstract}
Museums and community tourism become a strategy to preserve, rescue and revalue the cultural tourist heritage. The objective of the research was to analyze the importance of community museums in Potosí - Bolivia, for the preservation of the wealth of the towns and the strengthening of tourism. It responds to a qualitative, cross-sectional and descriptive study that applied the ethnographic methodology in three rural communities in the municipality of Potosí: Huari Huari, Paranturi and Manquiri.

The results show: heritage wealth dating from colonial times; insufficient public efforts aimed at the preservation of the historical heritage; knowledge, concern and interest in this regard on the part of the community members. It is concluded that there is a need to strengthen community tourism and have political strategies that preserve and protect the heritage present in the identity, natural, archaeological and architectural wealth of the peoples.
\end{abstract}

Key words: Community museum; Tourism; Preservation; Heritage; Cultural 
INTRODUCCIÓN

En Bolivia, la lucha por la preservación del patrimonio de los pueblos se concreta en la construcción de museos comunitarios, en ellos las comunidades ven una manera de conservar su riqueza natural, arqueológica y cultural. Tal es el caso del municipio de Potosí, que se caracteriza por contar con diversas comunidades con particularidades históricas, culturales y naturales; la identidad, el acervo cultural, la arquitectura, haciendas y capillas, que datan de la colonia, monumentos arqueológicos y pequeños espacios convertidos en "museos"; sin duda, forman parte de una riqueza patrimonial inimaginable, acompañado de las costumbres y tradiciones de un pueblo, que a la vez fortalecen el desarrollo local. Es necesario buscar nuevas alternativas que refuercen la oferta turística, con estrategias que promuevan la preservación y potencien los museos comunitarios andinos como oferta turística.

En estos espacios se da poca importancia al rescate, cuidado, preservación y conservación de los museos comunitarios, encontrándose estos en completo deterioro; si bien los comunarios se esfuerzan por preservar su identidad y aquello que les representa, no se cuenta con el apoyo necesario para fortalecer estas iniciativas.

¿Acaso el potencial turístico con todas sus especificidades se concentra en la ciudad? ¿Por qué no se promociona y rescata la historia, la identidad, cultura y patrimonio natural de estos pueblos? ¿Dónde están las políticas de preservación de este patrimonio? Estas preguntas motivaron a elaborar el presente artículo, que tuvo como objetivo analizar la importancia de los museos comunitarios, para la preservación de la riqueza de los pueblos y el fortalecimiento del turismo. Con este fin la investigación se propuso: primero, identificar la existencia de museos comunitarios; segundo, describir el estado y condiciones; en tercer lugar, se analizó las posibilidades de impulsar el fortalecimiento, rescate y revalorización del patrimonio natural arqueológico y cultural de los mismos.

La investigación se realizó a partir de tres estudios de caso en distritos rurales del municipio de Potosí; primero, un templo y una hacienda colonial, ubicados en un lugar llamado Huari Huari, a 47 minutos de la ciudad de Potosí, con riqueza natural, histórica y cultural; el segundo, el Museo de Paranturi, ubicado a 3600 m.s.n.m., las casas datan de 1600, cuya construccion se centra en la piedra y la paja; por último, el Museo de Manquiri, en el Distrito 18 de la ciudad de Potosí, que tiene la presencia de documentos desde 1700. Cada museo presenta características particulares, con espacios geográficos únicos, atractivos turísticos, imponentes rocas, cavernas con pinturas rupestres y formaciones arqueológicas naturales.

En la investigación se dio importancia al museo comunitario entendido como un todo; todo lo que una comunidad puede ofrecer como atractivos turísticos naturales, paisajísticos, arqueológicos, arquitectónicos y además los objetos encontrados en sus diferentes comunidades y que hacen o forman parte de la historia y vida de cada comunidad desde mucho antes de la colonia.

\section{MATERIALES Y MÉTODO}

Se trata de una investigación de tipo cualitativo, de corte transversal y alcance descriptivo. La forma en como fue abordado el tema al interior de cada comunidad se inscribe 
en la metodología etnográfica, con bases teóricas que se fortalecen en el trabajo de campo con el uso de la entrevista y la observación participante, que permitieron complementar la información precisada. Dado que la etnografía ha superado su carácter descriptivo, a todo este proceso de recopilación de información le sucedió un segundo momento, el de análisis, reflexión y sistematización de lo vivido, para profundizar en lo que hace al objeto de investigación.

Asimismo, se utilizó la revisión documental, pues permitió hacer una fundamentación histórica de cada comunidad museo, lo que posibilitó acercarse a sus orígenes, además porque no se puede hablar de museo sin que este represente o muestre la historia de un pueblo. (investigaciones, documentos de cabildos 1500 y libros desde 1600). Los libros consultados fueron: Cañete y Domínguez (1952); Capoche (1585); Arsánz De Orsúa y Vela (1676), además de documentos del Archivo Nacional de Bolivia, archivo de la Casa Nacional de Moneda en Potosí y archivo del Arzobispado de Chuquisaca.

La construcción diagnostica fue realizada a partir de los aportes de autoridades y mama t'allas de las tres comunidades partícipes de los grupos focales, agrupados en dos sesiones: el primero, cuyo eje temático fue el patrimonio y turismo, unido a su conservación, preservación y revalorización; el segundo, el estado en el que se encuentran los museos comunitarios en las comunidades. La metodología Delphi, con entrevista a expertos, como el personal de desarrollo turístico de la Alcaldía Municipal de Potosí, permitió la validación de la investigación.

La visita domiciliaria y barrido de cada comunidad, para interactuar con la gente y para conocer sus preocupaciones e inquietudes de acuerdo con la temática. A su vez el trabajo de campo fue acompañado con una serie de fotografías in situ, que muestran los atractivos de cada comunidad. Las herramientas utilizadas fueron ficha de observación, guía de entrevista a informantes clave, cuestionario, cámara fotográfica y filmadora.

RESULTADOS

El trabajo realizado a partir de la observación, entrevistas, grupos focales y estudios de caso fortaleció la investigación permitiendo hacer una sistematización con datos reales de lo que acontece en cada comunidad donde se encuentra los museos de estudio. Se presentan los resultados.

\section{Patrimonio y turismo en las comunidades}

En relación al conocimiento del valor patrimonial y turismo, las respuestas muestran que los entrevistados de las tres comunidades de estudio, saben lo que es patrimonio, por lo que dijeron: "Patrimonio es todo lo que es nuestro, la cultura, costumbres, que tenemos", "... es lo mío, de mi comunidad, que nadie me lo puede arrebatar o puedo cambiar, es algo de todos, de los del pueblo pero que nosotros debemos conservar"; "mi identidad cultural con origen aimara, eso es mi patrimonio, mi cultura, los paisajes, los cerros".

Con relación a turismo manifestaron: "considero que es una oportunidad para que nos demos a conocer"; "el turismo puede ser bueno en la comunidad porque con ello evitaríamos la migración"; "el turismo es cuando gente nacional o extranjeros vienen y 
te visitan y vos tienes que ofrecerles algo 0 mostrarles todo lo que tienes".

Los comunarios consideran que es necesario capacitar o preparar guías turísticos comunitarios con jóvenes locales que se encarguen de la oferta y promoción de sus espacios; finamente, de los museos, expresan que son espacios donde pueden conservar todo lo que tienen y dar a conocer a los visitantes: "Para mí el museo es un espacio que me permite organizar todo lo que he encontrado en mi comunidad, como los utensilios de los chullpas, los topos, la waraka encontrada en las urnas. Así conservamos la memoria de nuestros pueblos"; otro comunario aporta "nos permite conservar la historia de quienes fuimos en el pasado. Aqui en el museo tenemos vasos, cuadros antiguos; entonces, para que no estén en las casas todos han contribuido con algo para formar el museo".

Las autoridades de la comunidad dijeron que, para la conformación de estos museos, pidieron la colaboración de toda la comunidad y recibieron donaciones de objetos antiguos. Consideran que con una oferta turística que incluya los museos y atractivos para generar fuentes de ingreso, evitar la migración y conservar todo su patrimonio.

En relación a los beneficios económicos que el turismo pudiera generar, las respuestas obtenidas apuntan hacia la generación de oportunidades de ingreso para la comunidad, sin embargo resalta la necesidad de impulsar emprendimientos productivos turísticos; por ello decían: "Todo tenemos para mostrar, falta que nos enseñen a hacerlo [...] yo quisiera ser guía de turismo en mi comunidad porque conozco muchos lugares también pinturas rupestres, no solo el museo, también las minas coloniales"; otra comunaria enfatizaba "todo se está perdiendo es necesario recuperarlo, dicen que es patrimonio, no entiendo, pero nadie hace nada ese día nomas hicieron fiesta ahora no vienen [...] ya nos han robado los cuadros y las autoridades no vienen a cuidarlos"; en el mismo sentido, otra comunaria comenta "...si nos enseñan podemos trabajar y pueden venir turistas y ese sería un nuevo ingreso para la comunidad, asi de repente nuestras wawas no se irían a la ciudad".

Si bien las respuestas expresan que, el turismo comunitario, incluidos los atractivos naturales y el museo, son una oportunidad de nuevas fuentes de trabajo, también muestran la preocupación por aprender a ofrecer lo que tienen, además de revalorizar y conservar su identidad, su cultura y su patrimonio. Esto porque el turismo requiere de un trabajo sistémico y planificado, además de mano de obra cualificada, para que pueda ser ofertado como ruta turística.

En relación a la promoción turística de estas comunidades, los datos muestran que sólo en porcentaje mínimo se trabajó para innovar y ofertar los atractivos de las comunidades, si bien existe una oficina denominada Turismo Comunitario que depende del Gobierno Municipal, el personal no abastece para atender a todos los distritos rurales de esta ciudad, centrando su atención en la promoción de la gastronomía típica, pero no así en la revalorización del patrimonio natural, arqueológico, cultural de cada comunidad.

Es el caso de estos museos que, si bien son administrados por sus autoridades, los espacios son rústicos, no cuentan con la infraestructura necesaria, tampoco con guías destinados a su promoción y difusión. Por lo que manifiestan: Huari Huari, "Una sola vez 
vinieron a esta comunidad para saber si se podía encontrar los cuadros robados de la Casa de la Moneda, no volvieron más, ya pasaron años"; Paranturí, "nos dijeron que van a promover el turismo de la comunidad, hemos organizado este museo [...] lo hemos armado ahora está todo amontonado, no hay quien cuide"; Manquiri, "en mi comunidad nos dijeron igual que van a fortalecer el turismo hemos recorrido todo se tenía que hacer una ruta turística, pero nada yo creo que este año ya lo tendremos".

Por las preocupaciones emitidas en el grupo focal realizado por miembros de cada comunidad, fue necesario hacer una entrevista al responsable de Turismo Comunitario de la Dirección de Turismo de Potosí, quien decía: "Existen proyectos de preservación y conservación, por ejemplo, se pensó llevar adelante rutas turísticas en cada comunidad, ya se elaboró con el apoyo de la Universidad Autónoma Tomas frías y la Carrera de Geodesia, también se organizó los encuentros de Museos comunitarios de Bolivia, son pasos gigantes que estamos haciendo". Si bien se evidencia estas propuestas, lamentablemente en las comunidades de estudio no se cuentan con las mejoras correspondientes observando un total ausentismo de estos.

Haciendo referencia al estado en el que se encuentran los museos, unos están mejor conservados que otros, indicaron los entrevistados. esto se debe a que las responsabilidades para mantener en buen estado los lugares turísticos, no están correctamente definidas. Al respecto expresan: "Hacemos lo que podemos para mantener nuestro museo"; "Vinieron de otras instituciones, pero es ese momento que prometen todo, teníamos que hacer una catalogación de todos los objetos. Pero no hay nada". La observación permite aseverar que hay descuido y dejadez por parte de las autoridades para conservar toda esta riqueza. $\mathrm{Si}$ bien los comunarios buscan reactivar el turismo mostrando lo que conservan, esto no es suficiente, pues se debe contar con políticas de preservación y de restauración del patrimonio arquitectónico, y arqueológico de las zonas, considero que para ello se debe buscar alianzas institucionales que planteen planes estratégicos en la temática en cuestión, con el fin de lograr sostenibilidad en la oferta turística.

\section{Figura 1}

Museo Paranturí. Jarra con pitón

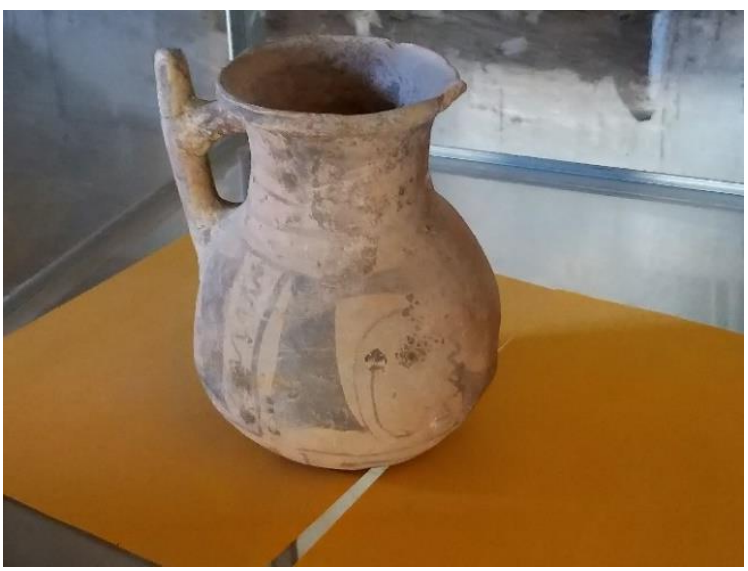


La Figura 1 representa a uno de objetos que se encuentran en el museo de Paranturí, parte de los restos hallados en la cumbre del cerro Pukara. Al respecto los comunarios manifestaban: "Nosotros tenemos un museo en un cuarto, pero [...] se ha caído el techo y esta todo amontonado, son cerámicas, flechas, cuencos, creemos que es de los chullpas esto hemos encontrado aquí en Paranturí y nadie nos ayuda a conservarlo"; "viene gente y cava en busca de restos arqueológicos y se lo llevan nunca nos dejan nada, hemos hecho el museo, pero no está ordenado, necesitamos que nos ayuden a cuidarlo"; "por la construcción de la escuela este espacio quedo en nada [...] hemos pedido hasta cansarnos para que nos ayuden a rescatar lo que tenemos y nos ayuden a construir un museo andino comunitario, hay propuestas ideas, pero nada más", expresan preocupados y molestos los entrevistados.

\section{Conservación, preservación revalorización del patrimonio}

En lo que respecta a la preservación y conservación de su identidad cultural, el patrimonio natural, arqueológico y arquitectónico, es un pedido constante por autoridades y miembros que conforman las tres comunidades de estudio. Decían los pobladores de Paranturí: "Todo lo que tenemos lo tratamos de cuidar, pero vienen a los chullpares y se han llevado vasijas tapadas, no sabemos que contenían, les hemos encontrado a mucha gente cavando en la noche"; en Huari Huari, "La iglesia estaba llena de cuadros yo he estudiado turismo y se identificó a dos cuadros de Melchor Pérez de Olguin, desaparecieron eran grandes desde el suelo al techo".

\section{Figura 2}

Manquiri: Cueva de Puka Ala con pinturas rupestres

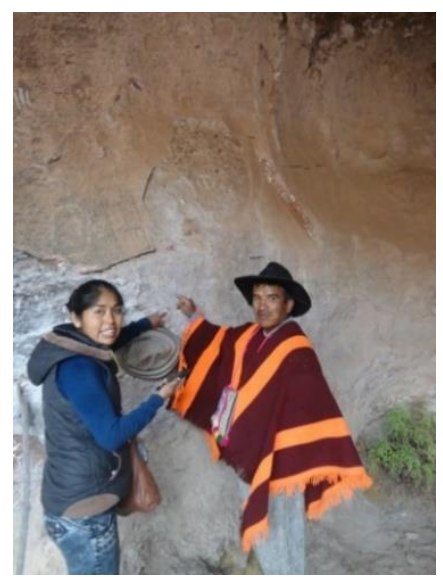

En la Figura 2, se puede apreciar a una de las autoridades que a la vez hace de guía de turismo, desde Manquiri, hasta la cueva de Puka Ala, donde se encuentra las pinturas rupestres; él se expresa así: "vienen, visitan y se van, nos quedamos en el olvido [...] nadie atiende de manera urgente estas necesidades, para su conservación". Cuentan con una pequeña ruta turística que ofrecen a los pocos visitantes que llegan a estos lugares, también 
hicieron un recorrido con señalética en el caso de Manquiri y la comunidad de Thamari para llegar a las pinturas rupestres, que de a poco se están destruyendo.

\section{Figura 3}

Pinturas rupestres de Puka Ala

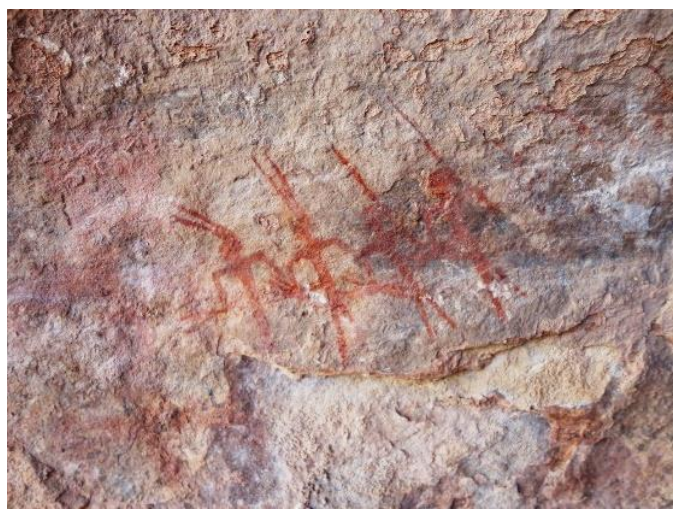

La Figura 3 muestra la presencia de hombres con flechas de color rojo ocre, por sus particularidades pareciera que fuesen de la época inca, encontradas en la Cueva de Puka Ala.

\section{Resultados de los estudios de caso - Museos Comunitarios}

La investigación permitió dar a conocer rasgos importantes de los espacios convertidos en museos comunitarios, resaltando su riqueza histórica, turística, natural, cultural y patrimonial, para lo cual fue importante estudiar su historia desde su presencia en la colonia, hasta la actualidad, enriquecida con leyendas y tradiciones propias de cada comunidad.

\section{Museo - Templo de Huari Huari}

La revisión documental, en libros y documentos del archivo de la Casa Nacional de La Moneda, citan al templo de Huari Huari, en poder que se otorga de esta comunidad a una capellanía, el 7 de marzo de 1635 (ANB, 1635). Para profundizar en su historia, se entrevistó a "los mayores"; según expresan los comunarios "ellos son los que saben de nuestros antepasados, a ellos les contaron sus abuelos y así se transmitió nuestra historia, ahora se está perdiendo". Otro entrevistado acota: "a los jóvenes no les importa, se van. Aquí nosotros hemos aportado no sólo a Potosí sino a Bolivia, con la minería por eso hay minas coloniales". Con relación al origen de la comunidad indican que tienen conocimiento del último hacendado: "sabemos del último patrón Walterspiel, todo esto era hacienda y la capilla parte de la casa grande".

El Templo Huari Huari conserva una riqueza patrimonial, reflejada en cuadros, esculturas, paredes, techo, campanas desde la época colonial. Estos espacios fueron declarados atendiendo a su valor histórico; constituyen un elemento alternativo y manifestación popular con carácter turístico cultural, como Patrimonio Arquitectónico, 
Histórico y Cultural (Campos, 2017). A la fecha no se encuentran conservados.

El templo alberga cuadros con características coloniales. Según Jaita (2013), algunos cuadros son de Cecilio Guzmán de
Rojas. Expertos de la Dirección de Turismo del municipio de Potosí, consideran que alguno de estos pertenece a Melchor Pérez de Olguín, por la forma de pintar los rostros que eran propios de este artista.

\section{Figura 4}

Templo Huari Huari. El Niño de la espina

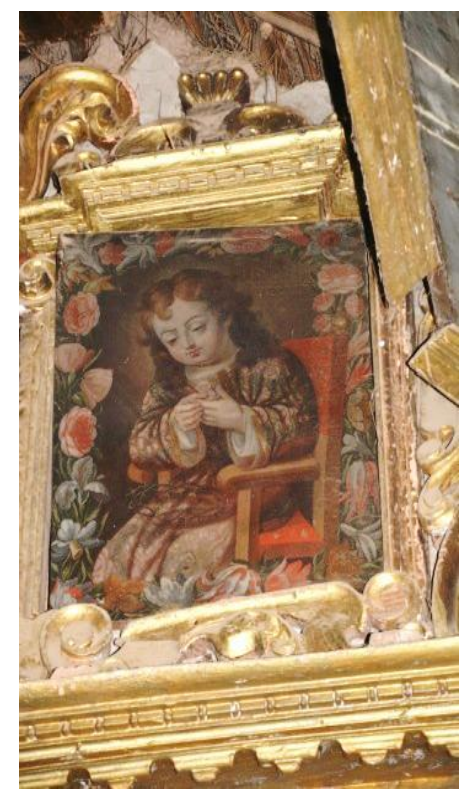

La Figura 4 se encuentra en la parte superior, lado derecho del altar mayor del Templo de Huari Huari. Por la similitud encontrada con cuadros que se encuentran en el museo Santa Teresa de Potosí, se puede afirmar que es el Niño de la Espina.

\section{Figura $\mathbf{5}$}

Templo de Huari Huari (sin nombre).

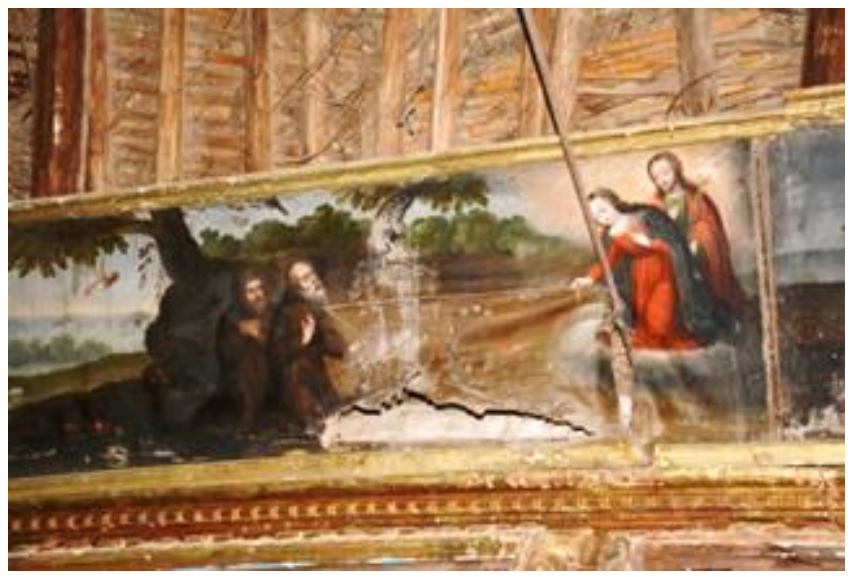

MAYA. Revista de Administración y Turismo 
La Figura 5 se encuentra en la parte lateral y superior del templo, no se visibiliza el autor del cuadro, sin embargo, representa la visita de los franciscanos a José y María, el momento en que ella rescata a uno de los franciscanos estirándole del cíngulo que trae consigo.

Si bien no se conoce a ciencia cierta su precedencia, resalta la relación con la vida de San Francisco. Existen cuadros que se encuentran dañados, en mal estado y otros que fueron arrebatados de las paredes de alrededor de esta capilla, conservándose aún el marco de los cuadros tallados y bañados en pan de oro.

Al respecto, los entrevistados manifiestan: "No están conservados porque no conocíamos el valor histórico ni lo que representaban los mismos, por ello alguien se los robó, recién sabemos que todo es colonial e importante conservarlos"; "todo de la hacienda se perdió era el museo de la comunidad, los ángeles de la iglesia, imágenes, esto de 1700 está escrito, pero se está desapareciendo, pido señorita puedan venir las autoridades a preservar todo lo que tenemos". Huari Huari cuenta con atractivos turísticos con formaciones rocosas, farallones, Wairas u hornos, cuevas de gran tamaño, acompañadas de las leyendas propias del lugar cuyas historias transmitidas de generación en generación se constituyen en patrimonio histórico.

\section{Museo - Santuario de Manquiri}

Oculta entre montañas de color rojizo, se encuentra una construcción que data de la colonia, es un santuario adecuadamente conservado que está ubicado en el Distrito 18 a 15 kilómetros al este de la ciudad de Potosí, denominado Manquiri (Figura 6). En el exterior del templo se puede observar la imagen de un cristo empotrado en una roca. Su valor estético y arquitectónico hacen que este santuario se convierta en un valioso atractivo turístico, cultural y religioso importante, al igual que el museo comunitario ubicado al interior de la hacienda. Ambos son parte del patrimonio arquitectónico, material, histórico y cultural, declarado por Ley Municipal en marzo de 2017.

\section{Figura 6}

\section{Manquiri: Santuario de Manquiri}

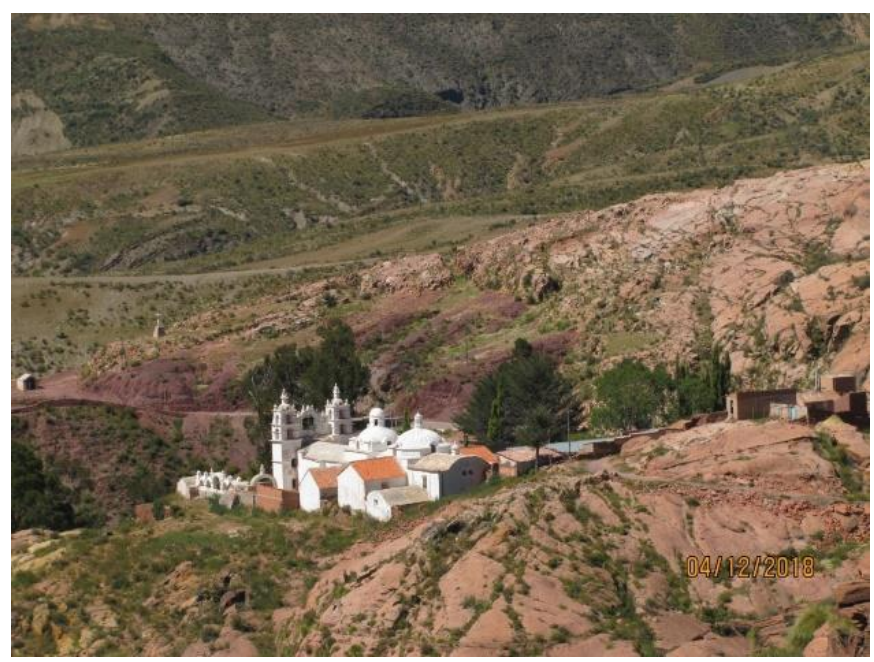


Con relación a los objetivos que se deben encarar, las autoridades indican: "después de varios años de lucha con autoridades y con descendientes del último patrón de apellido Zamora, se logró que la hacienda pase a manos de la comunidad y posterior a ello abrir el museo"; "falta conservarlo y colocar vitrinas para que se mantengan, ahora muchos objetos están en el suelo". Manquiri cuenta a su vez con atractivos turísticos como las pinturas rupestres, se manifiesta la necesidad elaborar una ruta turística como oferta para el visitante: "...en el santuario tenemos un Cristo Milagroso y la gente viene incluso desde el exterior a visitarlo, entonces nos estamos organizando para promocionar el turismo, pero necesitamos de apoyo sobre todo que nos capaciten que nos enseñen a ser guías de turismo"; "no conocemos nuestra historia y cómo podemos hablar de patrimonio y turismo si no se mis raíces, recién ahora con lo que leíste de nuestros documentos sabemos que existimos desde antes de 1500".

\section{Figura 7}

Museo Manquiri: Vestimenta típica de la comunidad

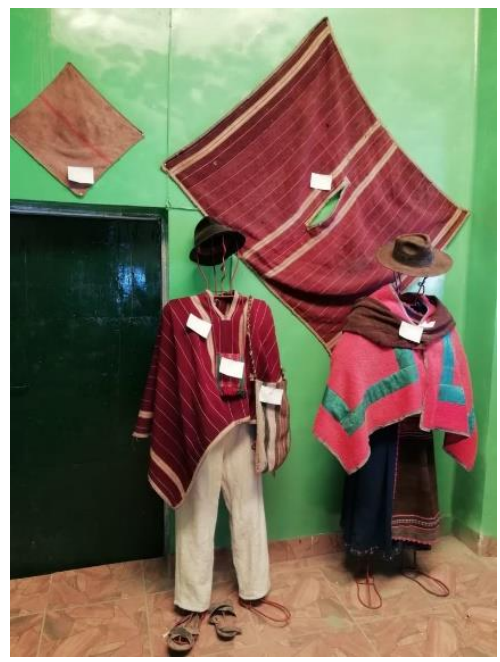

La Figura 7 resalta la vestimenta típica elaborada por los miembros de la comunidad, utilizada por sus ancestros, resaltando en ellos el sombrero de tres hoyos, los ponchos, el acsu y almilla en la mujer, la calzona y chuspa en el varón. Este museo ubicado en la comunidad de Manquiri, se encuentra mucho más organizado, está abierto al público desde junio de 2018, dividido en 7 salas con mapas cartográficos o rutas turísticas que ofrece la comunidad al visitante, además de ornamentos, artesanías, platería, alfarería, y un archivo con documentos desde el tiempo de la colonia, que entre sus hojas desgastadas por los años narran la historia de esta hacienda y del Cristo de Manquiri. 


\section{Figura 8}

Turicaya Grande: Cruz sin nombre

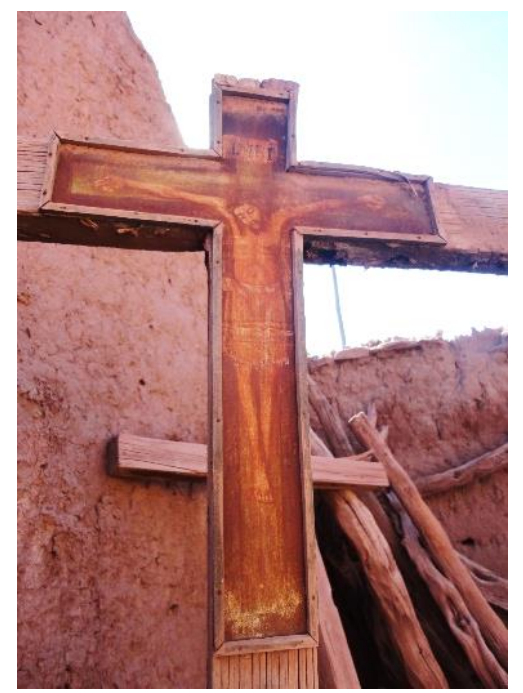

La Figura 8, representa una cruz, en ella se visualizan dos pinturas: en la parte superior Jesucristo clavado en la cruz; y en los pies María, su madre.

En la comunidad de Turicaya Grande perteneciente al Distrito 18 de Manquiri, se encontró lo que queda de una hacienda, en cuyos restos se mantiene aún la estructura como esqueleto de adobes de la capilla; está sin techo, abandonada y desecha. Al lado de ella, en otra habitación, se conservan algunos objetos religiosos y cuadros antiguos en mal estado, descuidados, dañados por los insectos, el viento y el agua; además de una campana, una lámpara, candelabros, se advierten restos de esculturas de santos o ángeles tallados en madera que remontan a la época colonial; además, los que saben de su existencia desconocen su valor.

De aproximadamente dos metros, se tiene una cruz de madera entre otras que están pegadas a la pared, en ésta se advierte la presencia de dos cuadros pequeños de $30 \mathrm{~cm}$ de alto, de aluminio y grabados en lata; primero, el dibujo de un Cristo crucificado; segundo, al pie de este la virgen María. Ambos guardan el mismo tono de color, la cruz por sus características muy particulares puede ser de la época colonial. Este recorrido se realizó con el apoyo del sub-alcalde del distrito de Manquiri.

\section{Museo de Paranturí}

Otra muestra de rescate del patrimonio es la comunidad de Paranturí, que conserva un pequeño pero importante museo arqueológico con más de 100 piezas diversas de cerámica, vasos ceremoniales, restos óseos, puntas de flechas, cuentas y topos que a por sus características se puede decir que pertenece a la época incaica, empero se necesita de un estudio minucioso para determinar la época y origen de quienes vivieron en el lugar. En la cima del cerro Pucara, se evidencia restos de lo que en otro momento sería una ciudadela, lugar donde habitaban las chullpas, anterior a los incas. 


\section{Figura 9}

Museo de Paranturí: Topos y cuentas (chullpas)

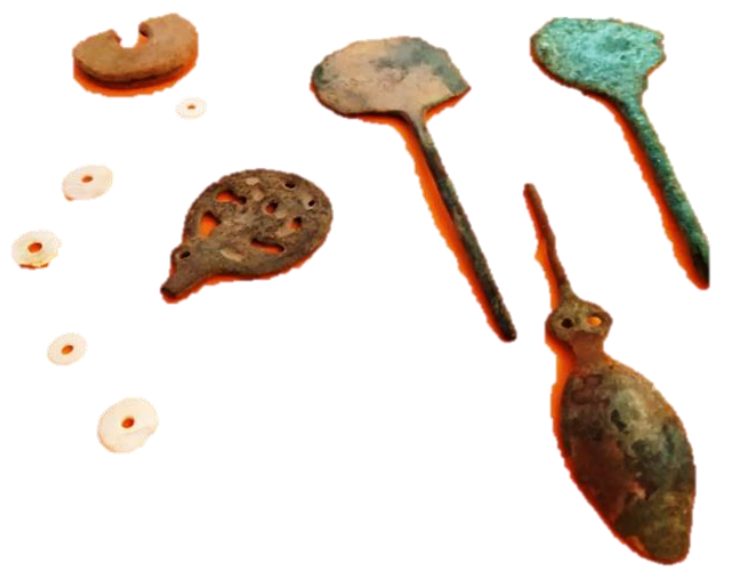

Ese museo se debe a la iniciativa de un grupo de estudiantes de la comunidad, manifiestan los entrevistados, quienes reunieron los diferentes objetos que conserva e hicieron unos pedestales para exponerlos en una habitación que se ubica en la escuela de la comunidad, cuyo objetivo es el resguardo de los objetos encontrados. Según el testimonio de los comunarios: "Se lo estaban llevando, todo lo que teníamos, queda poco y nadie hacia nada"; "yo vi estos topos eran de plata, porque en este lugar hay venas de plata, de un día para otro desaparecieron"; "Son nuestras raices, nuestros ancestros, antepasados, pedimos que respeten nuestra identidad, nuestra cultura y nuestro patrimonio".

A pocos metros del pueblo se encuentra Ckuchi Pujio, con restos de un complejo funerario andino preincaico, cuyas piezas encontradas también se exhiben en el museo de la comunidad. Sus antiguos habitantes hicieron estas excavaciones en forma cilíndrica para enterrar a sus muertos en posición fetal, acompañados de una serie de piezas de alfarería, tejidos, entre otros. Al respecto indican: "Ese cementerio es de los chullpas, la gente un tiempo han venido $y$ han hecho excavaciones, cuando era pequeño íbamos a pastear ovejas y hallábamos ollitas aquí en el cementerio, o cuando estamos arando".

Finalmente, estos resultados permiten aseverar que los museos comunitarios o cada sección de estas comunidades son potenciales turísticos y patrimoniales de Potosí, que son admirados por los comunarios, las autoridades y los turistas nacionales y extranjeros que han podido visitar instalaciones. Empero, poco se hace para conservar esta gran riqueza.

\section{DISCUSIÓN}

En ciudades como Potosí, a las que para efectos de promoción turística la Secretaría de Turismo ha llamado coloniales, se cuenta con un patrimonio edificado de gran riqueza, cuyo origen se remonta a la época colonial. La traza de calles y espacios abiertos, la arquitectura, las manifestaciones culturales como: fiestas, tradiciones, oficios y artesanías, constituyen un 
patrimonio invaluable que es fundamental conservar como raíz y esencia de identidad cultural y que deben y pueden aprovecharse racionalmente, a través del turismo, para apoyar y estimular la economía local, así lo mencionan autores como Hernández (2020).

Para comprender lo mencionado es necesario entender que en el campo y la ciudad el patrimonio es una fortaleza, al respecto la (UNESCO, 2011) menciona que es necesario preservar este valor para las próximas generaciones, porque son parte y pertenecen a un país, una tradición o un modo de vida.

El patrimonio incluye entornos naturales y culturales. Abarca paisajes, sitios históricos, arquitectónicos, arqueológicos, saberes y conocimientos de los pueblos, de su propia identidad. Un concepto valioso para esta investigación fue el expuesto por (ICOMOS, 1999), la memoria colectiva y el patrimonio cultural es insustituible e importante base para el desarrollo futuro de cada pueblo; menciona que las costumbres, las tradiciones y la expresión de un pueblo también son patrimonio, es decir, el patrimonio no sólo responde a los rastros materiales del pasado (Bonfil, 2004). En este marco, si una ciudad de configuración colonial es un patrimonio histórico singular y único, es "un museo abierto", por tanto, es posible potenciar el turismo a través de este atractivo patrimonial.

Al respecto, la Ley 530 de Patrimonio Cultural Boliviano lo define: "Es la institución cultural permanente al servicio de la sociedad y de su desarrollo, abierta al público y que adquiere, conserva, investiga, comunica, difunde $y$ exhibe el patrimonio inmaterial $y$ material de los pueblos y su entorno natural, con propósitos de estudio, educación y deleite al público" (Asamblea Legislativa Plurinacional, 2014). Cuando se habla del museo como un espacio que difunde y expone los testimonios materiales, se enfoca a los museos como transmisores de cultura; espacios que entre sus objetos conservados se vaya manteniendo y tejiendo su historia, un medio de comunicación y transmisión de mensajes de lo que otros fueron $o$ habitaron en estas tierras y que dejaron innumerables riquezas que medianamente se logra descifrar.

Por tanto, siguiendo a Shephard (2009), un museo comunitario es un espacio donde los integrantes de la comunidad construyen un autoconocimiento colectivo, propiciando la reflexión, la crítica y la creatividad; fortalece la identidad, porque legitima la historia y los valores propios, proyectando la forma de vida de la comunidad hacia adentro y hacia fuera de ella; fortalece la memoria que alimenta sus aspiraciones de futuro. En este marco, es importante hablar de turismo, porque a través de éste se da a conocer a los pueblos. No tendría sentido una comunidad que busca preservar su patrimonio sin la presencia del turismo, por ello los diferentes esfuerzos nacionales, departamentales y locales revitalizan la promoción y su oferta turística.

Aunque en el 2000 se promulgó la Ley de Promoción y Desarrollo de la Actividad Turística en Bolivia (Honorable Congreso Nacional, 2000), no fue sino hasta el 2009, con la puesta en vigencia de la nueva Constitución Política del Estado (Asamblea Constituyente de Bolivia, 2009), que tuvo lugar un nuevo marco de competencias entre los diferentes niveles de gobierno central, departamental, municipal, regional e indígena originario campesino; que requería una adecuación de los modelos vigentes de gestión del turismo. Este nuevo 
marco de competencias dio lugar a la vigente Ley General de Turismo "Bolivia Te Espera" (Asamblea Legislativa Plurinacional, 2012), que complementa la idea del turismo como una estrategia de desarrollo económico con "conceptos de sostenibilidad y turismo comunitario.

Es un pedido de todos, indica Campos (2017), el Gobierno Municipal de Potosí debe implementar políticas interinstitucionales públicas y privadas destinadas a proteger, preservar, promocionar y fortalecer estos espacios, como manifestación tradicional, popular y actividad turística y económica de interés municipal, contando para el efecto con los reglamentos y normas necesarias para evitar su destrucción.

Según lo expuesto se entiende que las investigaciones al respecto están presentes en diferentes espacios, se está en una lucha constante de preservación y se viene repitiendo. Los hallazgos en una comunidad de Manquiri ayudan a expresar la urgente necesidad de que las autoridades vuelquen sus miradas a los pueblos y vean el gran potencial turístico que lastimosamente se está perdiendo. Es primordial e imprescindible rescatar, revalorizar, preservar, restaurar y catalogar todo lo que se encontró en este lugar como patrimonio de esta comunidad.

Es en el lenguaje de las piedras que se ha escrito la historia de las ciudades, algunas de las cuales han sabido transmitir su mensaje y son un libro abierto para mostrar su historia, cultura y folklore, tanto a sus habitantes como a sus huéspedes, conformando parte importante de su patrimonio turístico. Es así como, las localidades tradicionales con sus referencias al pasado son los nuevos lugares que llaman al turismo alternativo. En este entendido, al ser Potosí una ciudad con mucha historia, riqueza y misterio; es quien atrae masas turísticas, por lo tanto, es imprescindible repensar, revalorizar y conservar lo que es nuestro.

En todo el proceso investigativo no se encontró documentación que referencien a estas comunidades o museos comunitarios andinos, lo que limita un tanto el análisis en el cuerpo de la discusión. Si bien se está fortaleciendo el establecimiento de museos comunitarios, estos se limitan al establecimiento de un ambiente; son necesarias acciones para su preservación, es decir, contar con propuestas turísticas sostenibles que revaloricen toda la riqueza histórica, identitaria, cultural, natural, arqueológica como patrimonio de los pueblos.

\section{CONCLUSIONES}

Los resultados obtenidos de la investigación son importantes, el estudio brindó datos exactos para que comunarios de los museos de estudio puedan ver la importancia de la conservación de su patrimonio histórico natural cultural, arqueológico.

Se identificaron los museos en mal estado de conservación, no se cuenta con señaléticas, ni servicios básicos, sin embargo, esto no significa que estos museos no puedan convertirse en ofertas turística para el visitante, ya que el emprendimiento, compromiso y esfuerzo de cada comunidad está presente; hace falta el apoyo institucional para fortalecer estas iniciativas que a la larga pueden ser potenciales turísticos que contribuyan a mejorar la economía de sus pueblos. Con ello se estaría dando solución, de alguna manera, a la emigración y al abandono de estos pueblos. 
Se identificó como primer tramo de ruta turística el recorrido de Manquiri a Puka Ala, empero, los accesos a las pinturas rupestres son inaccesibles, se requiere personal preparado o guías de turismo, los comunarios hacen esfuerzos por conservar y ofertar su patrimonio y exigen el compromiso de autoridades municipales a través de la oficina de Turismo Comunitario para acompañar los emprendimientos que son propios de autoridades de cada comunidad.

Existe urgencia en mejorar la infraestructura de los museos comunitarios, (servicios básicos, vialidad) y de apoyo (senderos, señalética turística rural, infraestructura turística), todo esto en concordancia con la generación de actividades turísticas. Se requiere, demás, contar con prestaciones de servicios turísticos de transporte, guías, hospedaje, alimentación, recreación y comunicación, como elementos de producción turística.

La observación directa de los templos permitió identificar, entre otras reliquias, cuadros con marcos en pan de oro, instrumentos e imágenes que datan de tiempos de la colonia. Para tener conciencia del valor total patrimonial es necesario partir de la elaboración de un diagnóstico situacional del patrimonio natural, histórico y cultural de los pueblos; que implica llevar adelante un inventario de todo lo que se conserva en todos los atractivos turísticos, fortalecidos con la elaboración de mapas de recursos turísticos y vías de riesgo. Es menester analizar las necesidades turísticas existentes para fortalecer las capacidades de los actores y gestores turísticos vinculados al territorio, que sean partícipes de la elaboración de planes y proyectos de desarrollo turístico de interés productivo. El rescate y revalorización comprende un proceso participativo de reconocimiento y revitalización de las culturas, para desarrollar actividades turísticas que favorezcan la preservación de todo lo que comprende el patrimonio de un pueblo.

\section{REFERENCIAS}

ANB, B. (1635). Documento poder que se otorga sobre vienes. Potosí

Campos, L. E. (11 de junio de 2017). Asentamiento que quiere cambiar la minería por el turismo. Huari Huari. Correo del Sur ECOS

Jaita, S. (2013). Resumen de Historia de antiguo, Ayllu Wuari Wuari. Potosí

Hernández, X. (16 de 04 de 2020). La imagen urbana de las ciudades como patrimonio histórico. En: http://www.cnmh.inah.gob.mx/ponencias/58 0.htm

UNESCO. (2011). Convención para la Salvaguardia del Patrimonio Cultural Inmaterial. París

ICOMOS. (1999). Carta Internacional sobre Turismo Cultural, La Gestión del Turismo en los sitios con Patrimonio Significativo. Consejo Internacional de Monumentos y Sitios. México

Bonfil, B. G. (2004). Pensar nuestra cultura http://observatoriocultural.udgvirtual.udg.m x/repositorio/handle/123456789/120117 134

Asamblea Legislativa Plurinacional. (2014). Ley $N^{\circ}$ 530, del 23 de mayo 2014

Ley del Patrimonio Cultural Boliviano. Estado Plurinacional de Bolivia, Bolivia

Shephard, C. C. (2009). Manual para la creación de museos comunitarios. New York: En línea wwwmuseoscomunitarios.org. Fundación Interamericana de Cultura y Desarrollo ICDF

Honorable Congreso Nacional. (2000). Bolivia: Ley de Promoción y Desarrollo en la 
Actividad Turística en Bolivia, 14 de abril de 2000. La Paz. Bolivia

Asamblea Constituyente de Bolivia. (2009). Constitución Política del Estado Plurinacional de Bolivia. La Paz. Bolivia
Asamblea Legislativa Plurinacional. (2012). Ley 292, Ley General de Turismo "Bolivia te espera" del Estado Plurinacional de Bolivia. Bolivia 